\title{
Asthma education and management programs in Canada
}

\author{
Robert L Cowie MD ${ }^{1}$, Lisa Cicutto PhD CAE ${ }^{2}$, Louis-Philippe Boulet MD ${ }^{3}$ \\ for the Patient Education Program Committee, Canadian Network For Asthma Care \\ ${ }^{1}$ Health Sciences Centre, University of Calgary, Calgary, Alberta; ${ }^{2}$ The University of Toronto, \\ Faculties of Nursing and Medicine, and the Michener Institute, Toronto, Ontario; \\ ${ }^{3}$ Institut de cardiologie et de pneumologie de l'Hôpital Laval, Sainte-Foy, Québec
}

RL Cowie, L Cicutto, L-P Boulet for the Patient Education Program Committee, Canadian Network For Asthma Care. Asthma education and management programs in Canada. Can Respir J 2001;8(6):416-420.

OBJECTIVE: To establish the number and type of asthma patient education programs throughout Canada.

DESIGN: National survey.

SETTING: Canada.

METHODS: Over a three-year period, contact was made with individuals and groups offering educational services for patients with asthma. Education given as part of a physician's consultation or a pharmacist's dispensing of medications for asthma was not considered a patient education program for the purposes of the survey. Contact was initially established by asking staff from well known asthma programs to provide lists of other such programs in their provinces or regions. Asthma programs were also identified from notices presented at Canada's Third and Fourth National Conferences on Asthma and Education. Lung associations, lay organizations and industry representatives affiliated with the Canadian Network for Asthma Care helped to supplement the list. Once identified, each patient education program was contacted by telephone and by mail to complete a 26-item questionnaire about their program. The province of Quebec was not included in the survey because it already had a province-wide, structured asthma education program and register.
RESULTS: Seventy-four asthma education and management programs were identified outside Quebec. Staff in these programs were registered nurses $(n=46)$, respiratory therapists $(n=48)$ and other health professionals $(n=21)$. Forty-one programs stated that at least one member of their staff had been trained as an asthma educator. In 71 programs, the initial patient encounter was of at least one hour's duration. Physician referral was required by 41 programs. The province of Quebec has a joint asthma education program provided by 114 asthma education centres throughout the province under the umbrella of the Quebec Asthma Education Network (QAEN). This comprehensive program is provided in hospitals and community centres by specialized educators - nurses, pharmacists or respiratory therapists - to patients referred by their physicians.

CONCLUSIONS: A three-year search for asthma education programs in Canada identified 74 patient education programs (outside Quebec) for an asthma population estimated to exceed 1.2 million. For the province of Quebec, an integrated asthma education program is provided through a network of 114 education centres - the QAEN. The present survey shows that there has been progress in establishing asthma education programs in Canada, although there are significant regional differences in the availability of such programs.

Key Words: Asthma education; Asthma management; Canadian asthma programs

Pour le résumé, voir page suivante 


\section{Enseignement et programmes thérapeutiques pour l'asthme au Canada}

OBJECTIF : Déterminer le nombre et le type de programmes d'enseignement sur l'asthme à l'intention des patients au Canada. MODĚLE : Enquête nationale.

CONTEXTE : Canada.

MÉTHODES : Au cours d'une période de trois ans, des contacts ont été établis avec des personnes et des groupes offrant des services d'éducation à l'intention des patients asthmatiques. L'enseignement dispensé par un médecin lors d'une consultation ou par un pharmacien au moment où il sert un médicament pour l'asthme n'a pas été inclus à titre de programme d'enseignement aux fins de l'enquête. Le contact a tout d'abord été établi avec le personnel chargé des programmes d'enseignement sur l'asthme connus, à partir desquels on a dressé la liste des autres programmes similaires dans les provinces ou les régions. Les programmes d'enseignement sur l'asthme ont également été identifiés à partir d'avis présentés lors des IIIe et VIe Conférences canadiennes sur l'asthme. Les associations pulmonaires, les groupes de consommateurs et les représentants de l'industrie affiliés au Réseau canadien pour le traitement de l'asthme ont également contribué à dresser cette liste. Chaque programme a ainsi été joint par téléphone et par la poste et invité à répondre à un sondage de 26 questions au sujet de son fonctionnement. La province de Québec n'a pas été incluse dans ce sondage parce qu'elle dispose déjà d'un programme et d'un registre structurés sur l'asthme à l'échelon provincial.
RÉSULTATS : Soixante-quatorze programmes d'enseignement et de traitement de l'asthme ont été dénombrés à l'extérieur du Québec. Le personnel de ces programmes se compose d'infirmières $(n=46)$, d'inhalothérapeutes $(n=48)$ et d'autres professionnels de la santé $(\mathrm{n}=21)$. Quarante-et-un programmes ont affirmé qu'au moins un de leurs membres avait reçu une formation pour l'enseignement sur l'asthme. Pour 71 des programmes, la première rencontre avec les patients dure au moins une heure. Quarante-et-un programmes exigent des consultations médicales. La province de Québec dispose d'un programme conjoint d'enseignement sur l'asthme offert par l'entremise de 114 centres d'enseignement sur l'asthme répartis sur l'ensemble de son territoire et chapeautés par le Réseau québécois d'enseignement sur l'asthme. Il s'agit d'un programme global offert aux patients, sur référence médicale, dans les hôpitaux et les centres de santé communautaires par des éducateurs spécialisés, infirmières, pharmaciens ou inhalothérapeutes.

CONCLUSION : Une enquête d'une durée de trois ans sur les programmes d'enseignement sur l'asthme au Canada a permis d'identifier l'existence de 74 programmes d'enseignement à l'intention des patients (à l'extérieur du Québec) pour une population asthmatique estimée à plus de 1,2 million. Pour la province de Québec, un programme intégré d'enseignement sur l'asthme est offert par l'entremise d'un réseau de 114 centres. La présente enquête confirme que la mise au point de programmes d'enseignement sur l'asthme a progressé au Canada, bien qu'il existe des différences régionales significatives quant à l'accessibilité à ces programmes.
$\mathrm{T}$ he majority of asthma consensus guidelines list education as an essential aspect of disease management (1-3). To be effective, asthma education should ensure that patients with the disease understand its modes of presentation, the role of their medication and the criteria for disease control. Patients with asthma also need repeated training to use their inhaler devices correctly, to monitor the course of this complex and variable disease, and to make appropriate changes to their medication $(4,5)$. Ideally, the asthma education process should lead to modifications of behaviour, including avoidance of asthma inducers and triggers, and improvement in the use of controller medications $(6,7)$.

It is widely acknowledged that educating patients suffering from asthma, as with other chronic diseases, requires special skills in education, and a current and appropriate knowledge of the disease and its management $(8,9)$. Studies show that patient adherence with environmental control and treatment is a major obstacle to effective management. Education, although not inevitably successful (7), is considered to be the only effective way to change behaviour toward improved adherence (10). Recognizing the importance of asthma education, the Canadian Network for Asthma Care (CNAC) dedicated resources to the training and certification of asthma educators. A National Asthma Educator Certification Program was developed to ensure that asthma educators have a baseline understanding of the disease and skills as an educator. The program requires that individuals successfully complete a CNAC-approved asthma educator training program and then pass the national certification examination. Those who successfully complete their training program and the national examination receive the designation of Certified Asthma Educator.

In the present survey, which is part of the CNAC commitment to improving asthma care, information was gathered concerning the availability and nature of Canadian asthma education programs.

\section{METHODS}

Since 1996, the CNAC has advertised its intention to develop a register of asthma patient education programs in Canada. The initial information about the proposed register was disseminated by the members of the CNAC to their individual organizations. These member organizations are the Canadian Lung Association, the Allergy Asthma Information Association, the Asthma Society of Canada, Health Canada, health professional organizations (physicians, nurses, pharmacists, respiratory therapists, physiotherapists, cardiopulmonary technologists) and the pharmaceutical industry. As each asthma program was identified, they were, in turn, asked if they knew of any other programs. The inquiry was advertised by verbal announcements, notices and posters at the Third and Fourth National Conferences on Asthma and Education (ASED 3 and ASED 4, respectively), which were held in 1997 (ASED 3) and 1999 (ASED 4). These biennial Canadian conferences are attended by most organizations and individuals associated with asthma management in general and asthma education in particular.

An initial register of asthma patient education programs was developed in 1997 and was available for review at 
TABLE 1

Asthma patient education programs identified in Canada as of May 2000

\begin{tabular}{lc}
\hline Province & Number of programs \\
\hline Alberta & 15 \\
British Columbia & 8 \\
Manitoba & 6 \\
New Brunswick & 4 \\
Newfoundland & 4 \\
Nova Scotia & 5 \\
Ontario & 28 \\
Prince Edward Island & 1 \\
Quebec & 114 \\
Saskatchewan & 3 \\
\hline
\end{tabular}

Details concerning these asthma programs are available on the

Web at <www.cnac.net> (Quebec programs [www.rqea.com])

ASED 3, where attendees were invited to examine and revise the data listed for their programs, and to add information about programs that were not included. A revised register was available at ASED 4, and delegates were encouraged to ensure that their programs were listed, to check that the listed information was correct and to notify the CNAC of any programs that were not included in the register.

Staff at each asthma education program were contacted by telephone or mail to complete a questionnaire requesting additional information about the program.

In 1998, the register of programs was posted on a Web site (www.cnac.net), which included a page on which information about additional programs or changes to listings could be entered.

Programs offered in Quebec were not included in the register because the Quebec Asthma Education Network (QAEN) was already established, and had its own register and Web site (www.rqea.com).

\section{RESULTS}

Information for the CNAC register had been submitted for 74 asthma education programs by May 2000 (Table 1). Each of these programs had been screened to ensure that it offered asthma education outside of the routine component of a physician's consultation or a pharmacist's provision of prescription medications.

The 74 programs employed 46 registered nurses, 48 respiratory therapists and 21 other health professionals, including physiotherapists, pharmacists and social workers. Of these 115 staff members, $76(66 \%)$ had received training as asthma educators. The nature of their training was not further defined. Staff with training in asthma education were available in 41 programs $(55 \%)$. Staff with formal training in asthma education were not available in 29 programs; this information was not clear for another four programs.

Adults and children were accepted in 47 programs, only adults were accepted in 15 programs, only children were accepted in 10 programs and no indication was given in two programs. Physician referral was required in 41 programs, and the remaining programs accepted patients who contacted the program directly. Although some programs listed multiple sites of operation, the majority (58 programs) were situated within a hospital, four were in physicians' offices and four were in other outpatient settings.

An initial individualized educational intervention was provided by 68 of the programs, although staff at some of these programs indicated that they might also educate groups of patients. Four programs listed only group education, and two did not provide an answer to this question. The initial educational session equalled or exceeded $1 \mathrm{~h}$ in 71 programs. Follow-up visits were offered in 66 programs.

The details regarding more specific aspects of the educational interventions indicated that the majority (98\%) had a full range of placebo inhaler devices available for instructional purposes. Only 55\% of the programs used these devices to allow the patients to indicate their preferred inhaler device. Diary cards to assist subjects with the monitoring of their disease were available in $89 \%$ of the programs. Action plans indicating when and how to adjust asthma medications according to asthma control criteria were discussed in $94 \%$ of the programs, and were provided for the patients to use in $78 \%$ of the programs.

Spirometry could be performed in 51 programs $(68 \%)$, and peak flow meters were available in the majority (73) of programs. Eleven programs (15\%) did not indicate that they used spirometry or peak flow meters to assess their patients.

A report was sent to the patient's physician in the majority of programs (92\%). All except two programs maintained a record of the patients receiving educational services.

Twenty-three programs $(31 \%)$ did not have any process for self-evaluation, and the question about the method used for evaluation was not completed for 11 programs (15\%). The usual methods used for self-evaluation were follow-up questions regarding asthma control or quality of life (34\%), and subject satisfaction (20\%).

The QAEN: One hundred fourteen asthma education centres (AECs), 75 of which are fully operational, are included in the QAEN. All AECs share a common educational program established by QAEN experts, reviewed by its scientific committee and based on the Canadian Asthma Consensus Guidelines (3).

The educational interventions are provided by nurses, respiratory therapists and/or pharmacists under the supervision of a designated physician. The AECs do not perform spirometry unless they are linked to an asthma clinic. Referral by a physician is encouraged, and, in all cases, the educator sends a report to the physician. All educators receive basic training in educating skills. One hundred thirty-two educators from 56 AECs are presently receiving training in the new educator program, which conforms with the CNAC criteria. Regular updates on asthma are also offered by the QAEN.

The intervention consists of an educational diagnosis, the verification of technique with inhaler devices, a discussion of control of environmental exposures, the development of 
an action plan based on symptoms or peak expiratory flow and information concerning the use of relevant community resources.

At the end of the educator-patient encounter, the educator evaluates the extent to which the initial objectives have been achieved. An educational follow-up is usually offered.

\section{DISCUSSION}

Asthma education is an essential component of asthma management; it should ideally be offered to all patients with asthma, but especially to those with the highest asthmaassociated morbidity (11).

The present extensive survey, conducted over three years, identified only 74 programs providing asthma education for patients with asthma in Canada outside Quebec.

The prevalence of asthma in Canada has been estimated to be between $4.1 \%$ and $11.2 \%$ in adults (12), and between $11.2 \%$ and $19.2 \%$ in children, and varies according to the definition of asthma used, the age of the subjects and the location in Canada (13). If we use the lowest estimated prevalence rate of $4 \%$, the total population with asthma in Canada (outside Quebec) would be approximately 900,000, and each of the programs we have identified would need to provide education for 12,000 patients. We hope that there will soon be additional asthma education programs in Canada, given that there are currently 372 Certified Asthma Educators, of whom 359 are outside Quebec.

Asthma education is a complex process (6), and should be provided by individuals who have training in patient education, and a current knowledge of the disease and its management. The time spent in the education program needs to be longer than the average physician-patient or pharmacistpatient encounter, and needs to be repeated on several occasions. The information must be accurate, current, well articulated and consistent among all caregivers, including physicians, pharmacists and educators.

A successful educational intervention must include the assessment of the individual's expectations, their readiness to modify their environment and their willingness to use medications according to an asthma action plan (3-5). Once the educator completes the assessment and identifies the educational objectives, a patient-centred intervention plan is developed with mutual agreement on its content. The content should include the following: information about asthma; the role of environmental measures focused on the elimination of asthma inducers and triggers; classes of asthma medications emphasizing those designed to control the disease; and the use of an asthma action plan (a decisional algorithm for adjusting medications). Practical aspects must be prominent and should include inhaler technique, methods for monitoring asthma and problemsolving activities to enable the individual to adjust medications from time to time. The education session should include the creation of a carefully written action plan and a reminder of the expected level of control that should be achieved. An education program should have or provide a contact person or service to allow the patient to obtain advice about their disease. Patients should be instructed to prepare for their next visit to their physician to ensure that they present and receive relevant information. The documentation provided to the referring physician by the educator should include information about the fears and concerns of the patient, and details of the management plan and expected outcomes.

Given the detail and intensity of the education process, it is clear that there is a need for many more asthma education programs if we are to apply the recommendation of our national guidelines that "asthma education is an essential component of asthma therapy (level I)" (3).

The asthma program in Quebec makes asthma education more accessible there than in the rest of Canada. A provincial network of AECs was established over the past six years as a result of contributions from the provincial government and other partners, including the pharmaceutical industry. The QAEN infrastructure offers centralized expertise in asthma education and decentralized educational services to more than 100 service points in Quebec. The educational program was developed jointly by all participants, updated by QAEN experts and reviewed by a scientific committee. This common program is shared by all AECs. A regional coordinator ensures the quality of the program. In addition, a provincial educators' program (Éduquer à Maîtriser l'Asthme) was developed, and is one of the CNAC-approved programs.

Among the current problems experienced by the Quebec network is a low referral rate by physicians, who have not always integrated asthma education into their practice. To ensure the referral of those in most need of education, patients being treated for asthma in an emergency department, those noted by pharmacists to be using excessive amounts of bronchodilator therapy and others who consult the Health Info service (Info-Santé) are now directly referred to the local AEC. Children with asthma may also be referred directly by school nurses.

The importance of asthma education is acknowledged by the Quebec government, and it is hoped that other provincial governments will follow this example. Data from Canada and elsewhere support the role of improved asthma control - the primary objective of education programs - in reducing the direct costs of asthma care, while improving the quality of life and economic contribution of patients affected by the disease (14-16). At present, there is no reliable funding for asthma education programs outside Quebec. Most programs are funded by donations, physicians, hospitals or local health authorities. As a result, the survival of these programs is tenuous. In addition to the provision of secure funding, legislation may be needed to allow asthma education programs conforming to a national standard to provide comprehensive services. Such services may include changing a delivery device, adjusting prescribed medications to conform with the national guidelines and developing action plans. Ideally, 
this should be done in collaboration with the treating physician. The association between an appropriately trained asthma educator and the physician has been identified as a key element of a successful asthma education program (17); such relationships will need to be developed carefully (18). In the first instance, asthma education programs must become more secure and more widely available before they can assume their role as an appropriate and routine part of asthma management. Efforts should then be made to persuade physicians that asthma education plays an important role in the treatment of this disease and to enable them to feel comfortable in their partnership with asthma educators.

Canada is a world leader in having a national asthma educators' certification program. This national program was developed and funded by the CNAC. The provincial governments now need to provide financial incentives and reimbursement for the provision of appropriate asthma education services. The need for improvement in the management of patients with asthma has been highlighted by two recent Canadian population studies $(5,19)$. These studies have shown that asthma is poorly controlled and is associated with significant morbidity in $60 \%$ of patients with the disease $(5,19)$. Given the data to support the important role of patient education in asthma management (3), it seems clear that asthma education programs need to be more widely available and easily accessible (18).

\section{CONCLUSIONS}

The present study has shown that there are 74 asthma education programs in Canada, in addition to 114 AECs sharing a common program within Quebec. Great progress has been made in the area of asthma education in Canada, and there is a need for the role of this intervention to be recognized and supported by provincial governments and other health care providers.

\section{REFERENCES}

1. National Heart Lung and Blood Institute. Clinical Practice Guidelines. Expert Panel Report 2: Guidelines for the Diagnosis and Management of Asthma. NIH Publication No. 97-4051. Bethesda: National Institutes of Health, 1997.

2. British Thoracic Society and others. The British Guidelines on Asthma Management. Review and position statement. Thorax 1997;52(Suppl 1):S1-21.

3. Boulet L-P, Becker A, Berube D, Beveridge R, Ernst P, for the Canadian Asthma Consensus Group. Canadian Asthma Consensus Report, 1999. CMAJ 1999;161(11 Suppl):S1-61.

4. Boulet L-P, Chapman KR, Green LW, FitzGerald JM. Asthma education. Chest 1994;106(4 Suppl):184S-96S.

5. Joyce DP, McIvor RA. Use of inhaled medications and urgent care services: study of Canadian asthma patients. Can Fam Physician 1999;45:1707-13.

6. Gibson PG, Boulet L-P. Role of Asthma Education. Evidence-Based Asthma Management. Hamilton: BC Dekker Inc, 2000:275-90.

7. Cote J, Cartier A, Robichaud P, et al. Influence of asthma education on asthma severity, quality of life and environmental control. Can Respir J 2000;5:395-400.

8. Boulet L-P. Asthma education: what has been its impact? Can Respir J 1998;5(Suppl A):91A-6A.

9. Cote J, Golding J, Barnes G, Boulet LP. Educating the educators. How to improve teaching about asthma. Chest 1994;106(4 Suppl):242S-7S.

10. Chapman KR, Walker L, Cluley S, Fabbri L. Improving patient compliance with asthma therapy. Respir Med 2000;94:2-9.

11. FitzGerald JM, Turner MO. Delivering asthma education to special high risk groups. Patient Educ Couns 1997;32(1 Suppl):S77-86.

12. ChenY, Dales R, Krewski D, Breithaupt K. Increased effects of smoking and obesity on asthma among female Canadians: the National Population Health Survey, 1994-1995. Am J Epidemiol 1999;150:255-62.

13. Millar WJ, Hill GB. Childhood asthma. Health Rep 1998;10:9-22.

14. Barnes PJ, Jonsson B, Klim JB. The costs of asthma. Eur Respir J 1996;9:636-42.

15. Hoskins G, McCowan C, Neville RG, Thomas GE, Smith B, Silverman S. Risk factors and costs associated with an asthma attack. Thorax 2000;55:19-24.

16. Weiss KB, Gergen PJ, Hodgson TA. An economic evaluation of asthma in the United States. N Engl J Med 1992;326:862-6.

17. Robertson R, Osman LM, Douglas JG. Adult asthma review in general practice: nurses' perception of their role. Fam Pract 1997;14:227-32.

18. Jin R, Choi BCK, Chan BTB, et al. Physician asthma management practices in Canada. Can Respir J 2000;7:456-65.

19. Chapman KR, Ernst P, Grenville A, Dewland P, Zimmerman S. Control of asthma in Canada: failure to achieve guideline targets. Can Respir J 2001;8(Suppl A):35A-40A. 


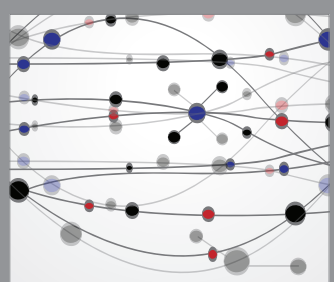

The Scientific World Journal
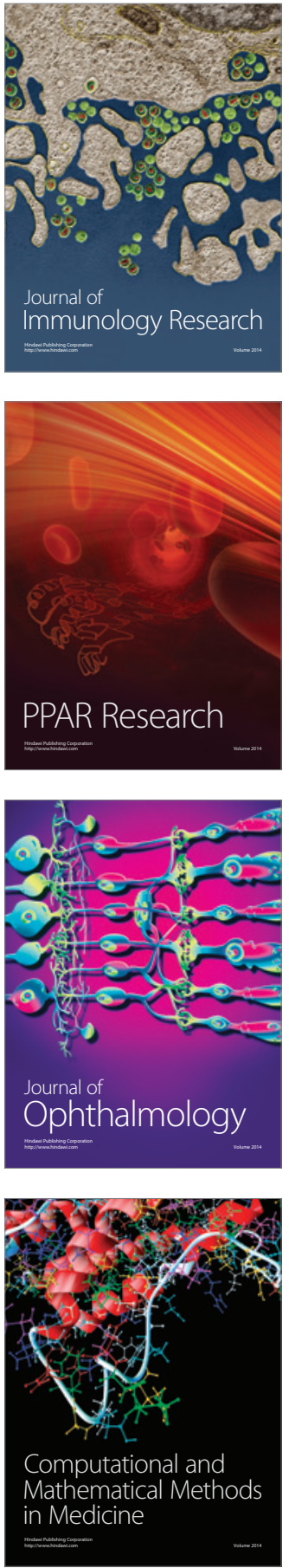

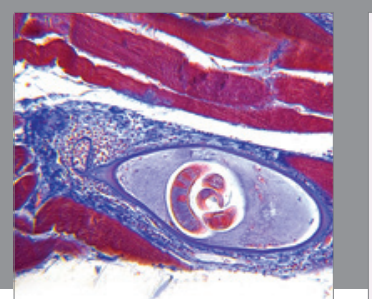

Gastroenterology Research and Practice

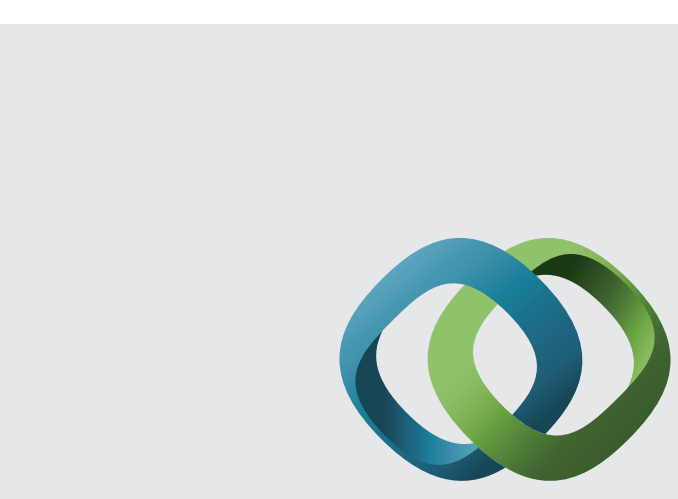

\section{Hindawi}

Submit your manuscripts at

http://www.hindawi.com
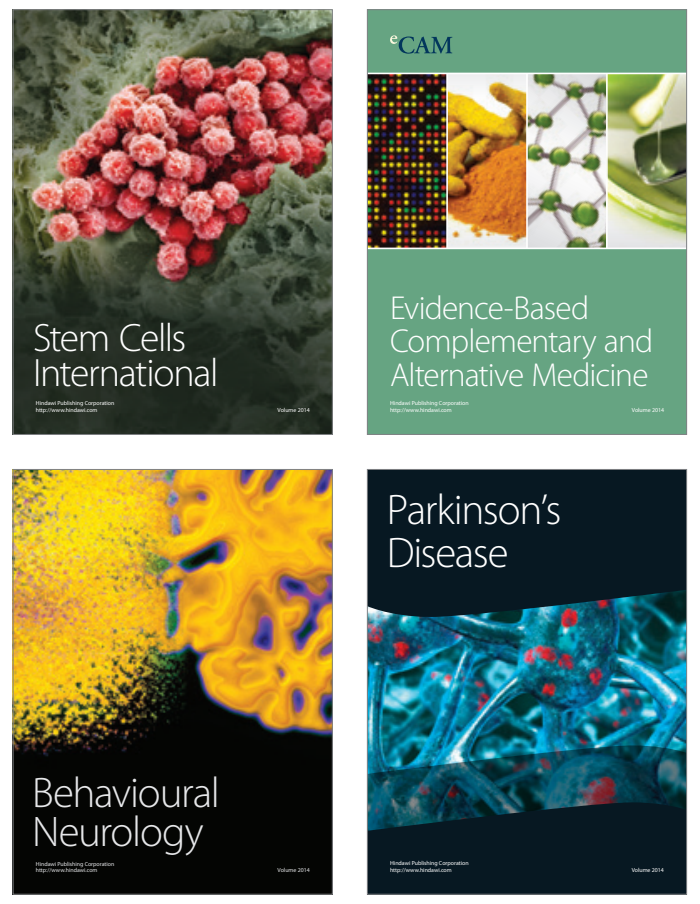
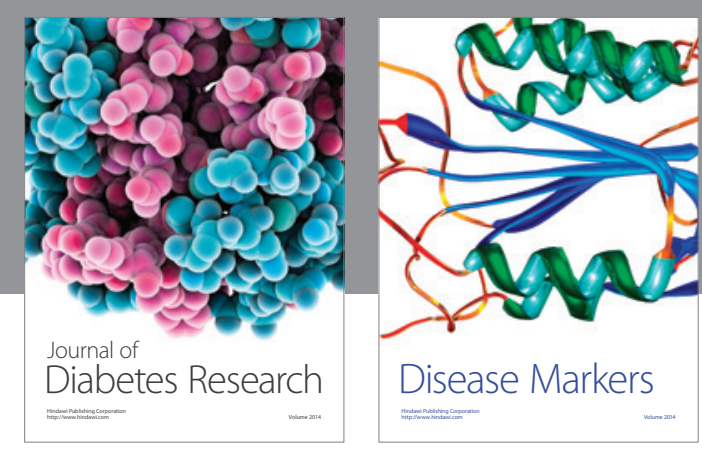

Disease Markers
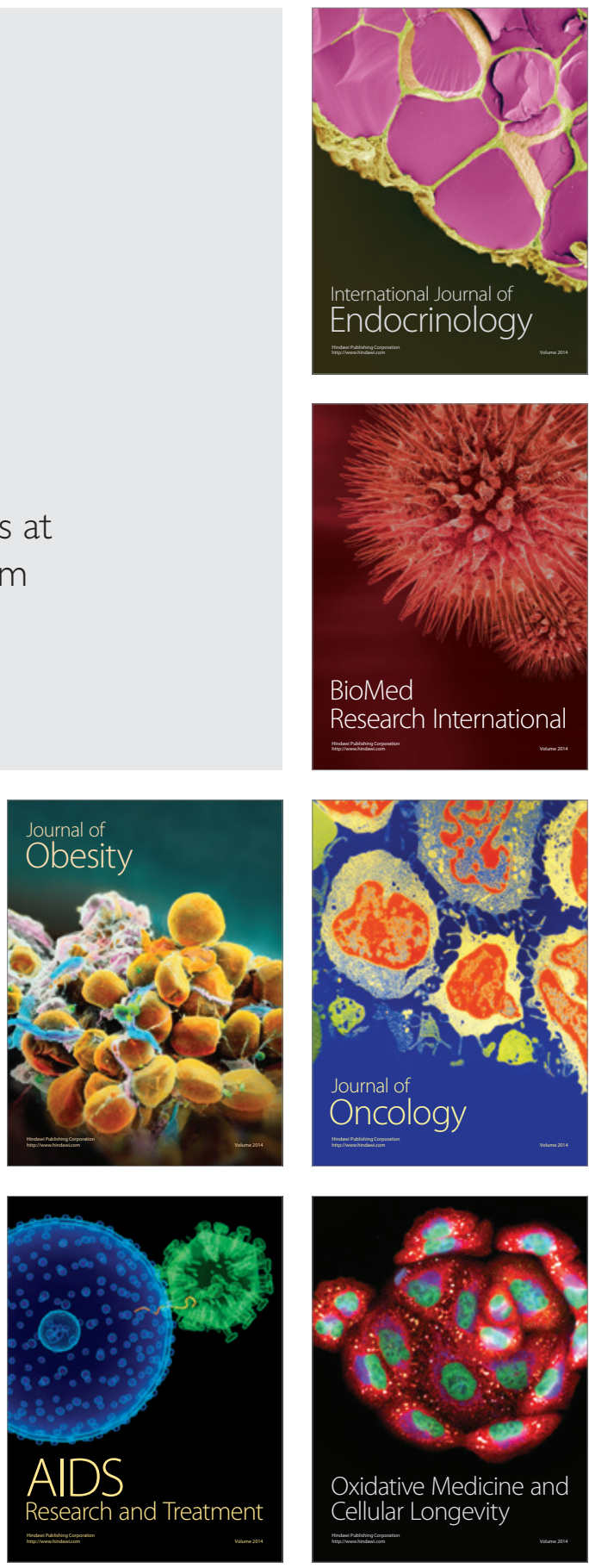